\title{
Translation Studies as an Interdiscipline: Plurality of Research Approaches
}

\author{
Lei Dai \\ Department of Translation and Interpretation \\ School of Foreign Languages \\ Wuhan University of Technology \\ Wuhan, China
}

\begin{abstract}
This study aims at examining the plurality of research approaches to Translation Studies given its interdisciplinarity. By comparing the four principal research approaches categorized by Chesterman - textual, cognitive, sociological and cultural- this paper critically reflects upon the properties of each approach, concluding that the maturity and stability of a research approach to Translation Studies is concomitant with their ad-hoc disciplinary perspectives. This research is therefore original by exhorting that translation researchers refrain from becoming a perfectionist who attempts to account for all the relevant variables of a real-life situation involved in a translation act. Instead, the kinds of hypotheses, models, and theories proposed in Translation Studies concern tendencies rather than mechanical cause-andeffect and appropriate research approaches should be selected according to a specific research nature, question and object. Understanding this is essential to exploring meaning and context, the central notions of translation.
\end{abstract}

Keywords-translation studies; interdiscipline; interdisciplinarity; research approaches

\section{INTRODUCTION}

As a human interlingual and intercultural communicative act, the practice of translating is long established, but as an academic discipline, the study of translation "only really began in the second half of the twentieth century" [1]. Literary studies and philosophy are among Translation Studies' earliest feeding disciplines, but with the increasingly important role played by translation in globally economic, social, cultural and technical communication, research from such interdisciplinary perspectives as sociology, cultural studies, aesthetics, economics, law, informatics, psychology, physiology and neurology are making much headway.

Translation Studies, in this sense, is "a house of many rooms and these different rooms are often simply different disciplinary perspectives on a common object - translation" [2]. As most other interdisciplines, Translation Studies is an open field connected to many other academic disciplines associated with the three traditional divisions of knowledge - humanities, natural sciences and social sciences. Moreover, the disciplinary territory has been expanding continuously with the increasing understanding of the nature

Sponsored by the Fundamental Research Funds for the Central Universities, PRC on the program "On the Foreignizing Translation Trend from the Perspective of Cultural Turn” (program code: 20110831). of translation.

Therefore, this paper argues that translation researchers adopt research methods according to their research areas, objects and questions, given the interdisciplinarity of Translation Studies and the plurality of methodological approaches. For this reason, the paper will review the major approaches to Translation Studies based on the categorizations of Chesterman [3], so as to argue for the maturity and stability of the research methods specific to their ad-hoc disciplinary perspectives.

\section{REVIEW OF RESEARCH APPROACHES TO TRANSLATION CATEGORIZED BY CHESTERMAN}

Chesterman classified research approaches to translation into four categories: textual, cognitive, sociological and cultural.

\section{A. The Textual Approach}

The textual approach regards text as written or oral linguistic data. The collection of text, like the field work of anthropologists for first-hand materials, focuses on source text (ST) and target text (TT), i.e. the translation product. Multiple editions of ST and TT can be collected in line with varied research aims.

As for textual categorization, the data is firstly classified as ST and TT. Then according to a specific research aim, the text features to be analyzed, such as certain lexicons or cultural items, are separated from the rest of the text. The last step of categorization is to align the parts to be analyzed into ST-TT pairs, which "can be further coded into bilingual parallel corpora" $[2,4]$. Textual analysis is primarily carried out through "close reading" and "stylistic analysis", methods principally used in comparative literature and the "text / corpus analysis based on contrastive / comparative analysis", a method often used in linguistics $[5,6,7]$ so as to explore the ST-TT relations in the designated corpora. Nowadays, the textual approach is seldom used alone. Instead, it is often used together with other approaches. Consequently, the specific method of analysis and its nature can only be decided by the specific research aim, the research object and the research approach(es) concomitant with the textual approach. 


\section{B. The Cognitive Approach}

Compared with the translation-product-oriented textual approach, the cognitive approach explores translation as a process, investigating such influences as the translator's thinking pattern, professional experience, personality, emotion, time limit and working conditions on the translatorial decision-making process, by means of positivist simulated experiments during which think-aloud protocols (TAP) and eye tracking are employed to collect both the explicit and implicit data from the subject interpreter.

"TAP" [8], proposed firstly by psychologists, asks the translator to verbalize her thought processes when translating, with everything recorded by the researcher. Data analysis is the same as interview in social sciences: the researcher transcribes the record into text which is then analyzed qualitatively. Eye tracking records how the eyes of the subject move during the translation process using specialized instruments. The length of fixation points and the dilation of the pupil may indicate the mental effort being made by the translator [9]. With regard to data analysis, a researcher may need to use such statistics software as SPSS for quantitative correlative analysis of the corresponding textual fragments and the moments when the translator is highly concentrating, namely seeking which specific parts of the text demand more mental efforts. However, "the final process of understanding and interpreting the findings is essentially an interpretivist qualitative research activity" [10].

\section{The Sociological Approach}

Likewise, the sociological approach surveys translation as a process. But differently, this approach particularly probes the human factors in the process of translation from the sociological perspective. Here, the "human" can refer primarily to the translator, such as studying a renowned translator, the socioeconomic status of translators in a specific society or period, the translator's mediation / intervention, the professional standards, development and social recognition of translation, translation ethics, etc.

Furthermore, the sociological approach can "regard translation as an event" [4], beginning with the appointment of a translator by the commissioner of the translation action and, ending with the ST translated and the TT published or handed only to the initiator of the translation action or certain readers for the sake of secrecy. Under such circumstances, the human factors can be further extended to those people and institutions closely connected and interacting with the translator, such as the ST author, the translation action initiator, commissioner, sponsor, press, government watchdog, TT reader, TT critic and other ST translators, who influence not only the translating process but even the translation product. Involving various human factors, the sociological often collects data with such ethnographic methods as interviews and questionnaires.

\section{The Cultural Approach}

The cultural studies approach (CSA) actually marks the advent of the cultural turn in Translation Studies, which analyzes text under "the greater cultural context" [11] by bringing translation into debate with critical and cultural theories related to ideology, deconstruction, rewriting, manipulation, feminism, post-colonialism, power, institution and etc.

For example, theories of rewriting and manipulation focus on the manipulation of social power and cultural ideology on the translating process; feminist theories show interest in understanding the relations between women's social status and translation and finding how to highlight female identities in and through translation; post-colonialist theories are concerned with vehement political issues such as race, nation, imperialism and hegemony so as to deconstruct the Western centralism and cultural hegemony by reinstating the former colonials the due respect for their own culture.

Usually a qualitative and hermeneutic analysis of the translation product can be carried out by integrating CSA with LA, macro with micro angles and, contextual with textual analysis, in order to "extend and challenge the basis of traditional conceptualizations of translation such as equivalence and meaning", thus enhancing one's understanding of the nature of translation $[1,12]$.

\section{REFLECTIONS UPON THE CATEGORIZATION}

Firstly, interpreting the research outcome is inevitably an interpretivist process with qualitative and hermeneutic methods used, which further decides that the research finding cannot be absolutely objective as long as humans are involved, no matter as researchers, objects or both. This point is even more asserted in translation studies, which involves multiple variables such as human, text and context and some abstract, fuzzy and fluid concepts such as language, culture and meaning. Studies on translation are even more complicated as translation, "very probably the most complex type of event yet produced in the evolution of Cosmo" [13], involves not only people's physiology but also psychology. So it is unrealistic to evaluate findings of Translation Studies with the precision pursued by natural or social sciences. It is argued that the objectivity of the research findings of Translation Studies, as the translatability of translating, is only relative.

Secondly, as a fledgling interdiscipline, Translation Studies owes most of its research methodology to other disciplines, which further decides that "the nature of change of Translation Studies" [14] should be fully considered when specific approaches are selected. With regard to humanities "with interpretivism as their methodological cornerstone" [6], the selection of specific approaches should not follow the black-and-white mindset as natural sciences and social sciences.

More often than not when it comes to the selection, collection, categorization, and analysis of data, it is difficult to pinpoint which method is used or from which discipline this method comes from in that No.1, these methods are per se evolving constantly for they are not only used in Translation Studies but also in many other academic disciplines; No.2, Translation Studies, as an interdiscipline, keeps expanding, with newly assimilated approaches interacting, conflicting and integrating with the existing ones, 
which promotes not only the development of Translation Studies, but also that of the human methodology, epistemology and ontology.

Since the advent of CSA to Translation Studies, a host of translation theorists are scathing about the textual approach, "using it as a scapegoat to blame for the ills that have befallen us in the study of translation" [2]. Some CSA theorists even ran to the extreme of deconstructing equivalence, a notion enshrined by textual theorists, for "they no longer believe the existence of such notions as meaning, equivalence, ST and TT' $[1,12]$. However, this paper argues that regardless of studying translation with CSA or other interdisciplinary perspectives, the researcher is destined to return to the lexical, syntactic and semantic dimensions of the text which embodies the interlingual and intercultural nature of the translation act. Separated from language, text and structuralism which are indispensable to the habitat of translation, translation would be relegated to superficiality. Conversely, CSA emphasizes describing and analyzing the text against the greater cultural context, thus maximally shunning the myopia incurred by using the textual approach alone.

\section{CONCLUSION}

In conclusion, Translation Studies has manifold research approaches. Some people view this as the immaturity of Translation Studies which is yet to consolidate its disciplinary position due to the predicament of lacking an eclectic methodological framework capable of accommodating a wide range of research interests [15]. Others encourage "the plurality of methodological paradigms" in that interdisciplinarity is instrumental not only to translation studies but also other relevant academic disciplines [12]. The paper argues that translation researchers refrain from becoming a perfectionist who "attempts to account for all the relevant variables of a real-life situation" involved in a translation act [6]. In other words, the kinds of hypotheses, models, and theories proposed in Translation Studies "concern tendencies rather than mechanical causeand-effect" [16]. Understanding this is essential to exploring meaning and context, the central notions of translation.

\section{REFERENCES}

[1] J. Munday, Introducing Translation Studies: Theories and Applications. London and New York: Routledge, 2012.

[2] B. Hatim, Teaching and Researching Translation. Harlow: Pearson Education, 2013.

[3] A. Chesterman, Towards Consilience? In K. Aijmer \& C. Alvstad (eds). New Tendencies in Translation Studies: Selected Papers from a Workshop, Göteborg 12 December 2003. Göteborg: Göteborg University, Department of English, 2005.

[4] G. Toury, Descriptive Translation Studies - And Beyond. Amsterdam and Philadelphia, PA: John Benjamins, 1995.

[5] K. Koskinen, How to Research EU Translation? Perspectives, 9(4), pp293-300, 2001.

[6] J. Williams and A. Chesterman. The Map: A Beginner's Guide to Doing Research in Translation Studies. Manchester: St. Jerome, 2002.

[7] J. Boase-Beier, A Critical Introduction to Translation Studies. London and New York: Continuum, 2011
[8] K. Ericsson and H. Simon, Protocol Analysis: Verbal Reports as Data. Cambridge and MA: MIT Press, 1984.

[9] S. O'Brien, Eye Tracking and Translation Memory Matches. Perspectives, 14(3): pp185-205, 2006.

[10] D. Remenyi, Case Study Research. Reading: Academic Publishing, 2012.

[11] S. Bassnett, S. and A. Lefevere, (eds), Translation, History and Culture. London: Pinter, 1990.

[12] A. Pym, Exploring Translation Theories, 2nd Edition. London and New York: Routledge, 2014.

[13] J. S. Holmes, Translated! Papers on Literary Translation and Translation Studies. Amsterdam: Rodopi, 1998.

[14] M. Tymoczko, Enlarging Translation, Empowering Translators. Manchester: St. Jerome, 2007.

[15] E. Crisafulli, The Quest for an Eclectic Methodology of Translation Description. In T. Hermans. Crosscultural Transgressions: Research Models in Translation Studies II : Historical and Ideological Issues. pp26-43. Manchester: St. Jerome, 2002.

[16] A. Pym, On the Social and the Cultural in Translation Studies. In A Pym, M. Shlesinger \& Z. Jettmarová (eds). Sociocultural Aspects of Translating and Interpreting. Amsterdam and Philadelphia, PA: John Benjamins, 2006. 